\title{
Retrievals of aerosol optical and microphysical properties from Imaging Polar Nephelometer scattering measurements
}

\author{
W. Reed Espinosa ${ }^{1,2}$, Lorraine A. Remer ${ }^{1,2}$, Oleg Dubovik ${ }^{3}$, Luke Ziemba ${ }^{4}$, Andreas Beyersdorf ${ }^{4,5}$, Daniel Orozco ${ }^{1,2}$, \\ Gregory Schuster $^{4}$, Tatyana Lapyonok ${ }^{3}$, David Fuertes ${ }^{6}$, and J. Vanderlei Martins ${ }^{1,2}$ \\ ${ }^{1}$ Department of Physics, University of Maryland Baltimore County, 1000 Hilltop Circle, Baltimore, MD 21250, USA \\ ${ }^{2}$ Joint Center for Earth Systems Technology, University of Maryland Baltimore County, 5523 Research Park DR, \\ Baltimore, MD 21228, USA \\ ${ }^{3}$ Laboratoire d'Optique Atmosphérique, UMR8518, CNRS, Université de Lille 1, 59655, Villeneuve d'Ascq, France \\ ${ }^{4}$ Langley Research Center Science Directorate, National Aeronautics and Space Administration, Hampton, Virginia, USA \\ ${ }^{5}$ Department of Chemistry and Biochemistry, California State University San Bernardino, 5500 University Parkway, \\ San Bernardino, CA 92407, USA \\ ${ }^{6}$ GRASP-SAS, Bat-P5, Université de Lille 1, 59655, Villeneuve d'Ascq, France
}

Correspondence to: W. Reed Espinosa (reedespinosa@umbc.edu)

Received: 28 October 2016 - Discussion started: 8 November 2016

Revised: 2 February 2017 - Accepted: 7 February 2017 - Published: 8 March 2017

\begin{abstract}
A method for the retrieval of aerosol optical and microphysical properties from in situ light-scattering measurements is presented and the results are compared with existing measurement techniques. The Generalized Retrieval of Aerosol and Surface Properties (GRASP) is applied to airborne and laboratory measurements made by a novel polar nephelometer. This instrument, the Polarized Imaging Nephelometer (PI-Neph), is capable of making high-accuracy field measurements of phase function and degree of linear polarization, at three visible wavelengths, over a wide angular range of 3 to $177^{\circ}$. The resulting retrieval produces particle size distributions (PSDs) that agree, within experimental error, with measurements made by commercial optical particle counters (OPCs). Additionally, the retrieved real part of the refractive index is generally found to be within the predicted error of 0.02 from the expected values for three species of humidified salt particles, with a refractive index that is well established. The airborne measurements used in this work were made aboard the NASA DC- 8 aircraft during the Studies of Emissions and Atmospheric Composition, Clouds and Climate Coupling by Regional Surveys (SEAC ${ }^{4} \mathrm{RS}$ ) field campaign, and the inversion of this data represents the first aerosol retrievals of airborne polar nephelometer data. The results provide confidence in the real refractive index product, as well as in the retrieval's ability to accurately deter-
\end{abstract}

mine PSD, without assumptions about refractive index that are required by the majority of OPCs.

\section{Introduction}

Aerosols, and their interaction with clouds, play a key role in the climate of our planet. Additionally, measurements of aerosols are crucial to a wide range of direct applications, ranging from the monitoring of clean rooms to the impact of air quality on public health. Despite the importance of these particles, obtaining accurate in situ measurements of their optical and microphysical properties has remained a significant challenge.

Optical techniques of particle sizing typically capitalize on the approximately monotonic increase in the amount of light scattered by a single particle as a function particle size. These instruments are among the most widespread and precise available, but the vast majority of optical particle counter (OPC) designs require significant assumptions about the aerosol being sampled. These simplifications result from the limited information content present in typical OPC measurements, which frequently sample scattered light over a single angular range, often 4 to $22^{\circ}$ (Pinnick et al., 2000) or roughly 30 to $150^{\circ}$ (Cai et al., 2008) in so called wide angle 
OPCs. These assumptions, generally regarding real refractive index, absorption and particle morphology can lead to significant biases in the resulting particle size distributions (PSDs) and generally constitute the bulk of the measurement error (Pinnick et al., 2000). Additionally, in situ measurements of many of these characteristics, like aerosol refractive index or particle sphericity for example, are still virtually nonexistent, especially at altitudes far from the surface.

A less common approach to characterizing particles is through polar nephelometer measurements of light scattering from an ensemble of particles over a large number of angular regions. This approach provides a large amount of information about the sample, reducing the total number of assumptions required and the resulting biases in the retrieved products. Unfortunately, deploying field instruments with these capabilities can be quite challenging, and airborne measurements of common aerosols using this technique have previously been unavailable. Additionally, the inversion of multiangular data is significantly more complex than the inversion of light-scattering intensity over a single angular range.

In spite of the complexities associated with multiangle measurements and the corresponding inversions, there have been several successful attempts over the past four decades to retrieve particle properties from polar nephelometer data. The first published inversion of this kind was made by Eiden in 1966, who used multiwavelength polarization data to retrieve the complex refractive index of an ambient aerosol, as well as match one of three predefined aerosol PSD models (Eiden, 1966). Jones et al. (1994) used intensity measurements to size monodisperse, polystyrene latex (PSL) spheres, as well as to determine their complex index of refraction. Intensity and polarization measurements of ambient aerosols made by the Tohoku University single wavelength polar nephelometer in Sendai, Japan have been inverted to obtain complex refractive index and number concentrations in six log-spaced size bins (Tanaka et al., 1983; Zhao, 1999). There have also been attempts to retrieve only the refractive index, while constraining the model's size distribution with a traditional particle sizer (Barkey et al., 2007, 2010). The converse approach was reported by Lienert et al. (2003), who took polarized measurements of sea spray and determined PSD by assuming a refractive index value expected for sodium chloride particles at the ambient relative humidity. Most recently, Sviridenkov et al. (2014) obtained both complex refractive index and PSD from three-wavelength intensity measurements made with a commercially available polar nephelometer. All of these retrieval efforts have assumed spherical particles, and all measurements were made in the visible spectrum, except in the case of Jones et al. (1994), who used measurements made in the near-infrared. The only polar nephelometer retrievals to incorporate a nonspherical component in the scattering model were performed by Dubovik et al. (2006), who fit laboratory measurements of desert dust.

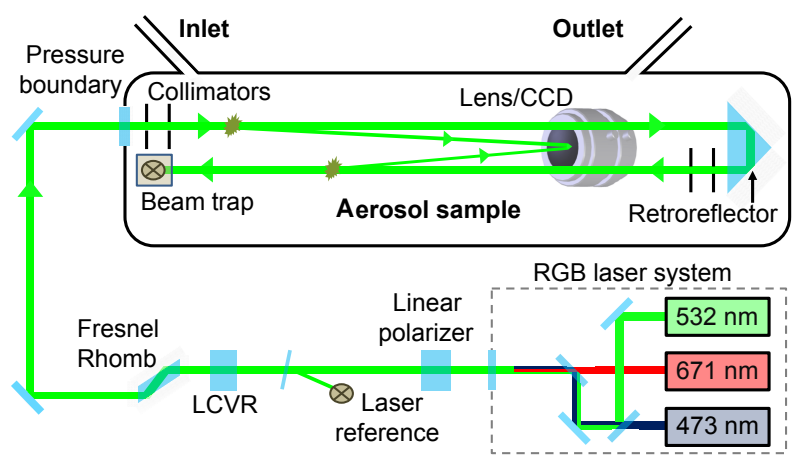

Figure 1. The PI-Neph instrument concept. Figure adapted from Dolgos and Martins (2014).

In this work we apply a complex inversion algorithm, specifically the Generalized Retrieval of Aerosol and Surface Properties (GRASP), to airborne and laboratory measurements made with the Polarized Imaging Nephelometer (PINeph), a multiwavelength, multiangle light-scattering instrument. The GRASP retrieval makes no assumptions about the number of modes in the size distribution or the complex refractive index, and it allows for both spherical and spheroidal scatterers. This represents a significant increase in complexity when compared to previous in situ scattering inversions. In addition to the generality of the retrieval, this work represents the first time that any aerosol retrieval algorithm has been applied to airborne polar nephelometer measurements. Furthermore, the ambient airborne measurements presented here were made in parallel to a large variety of independent instrumentation, allowing for very robust intercomparisons of the retrieved products.

\section{Inversion methodology}

Aerosol-scattering matrix elements are measured in situ with a polar nephelometer and feed into a microphysical retrieval algorithm in order to obtain aerosol size distribution, complex refractive index $(\mathrm{m})$ and a percentage of spherical particles. These measurements include a combination of artificially suspended laboratory data as well as airborne data taken over the continental United States during the Studies of Emissions and Atmospheric Composition, Clouds and Climate Coupling by Regional Surveys (SEAC ${ }^{4} \mathrm{RS}$ ) field experiment in 2013. GRASP, a versatile open source software package (http://www.grasp-open.com) capable of performing inversions on a wide variety of atmospheric optical measurements, was used to obtain the retrieved microphysical parameters. A detailed description of the GRASP retrieval algorithm and its capabilities can be found in Dubovik et al. (2011, 2014). 


\subsection{Polarized Imaging Nephelometer}

In an effort to advance in situ characterization of atmospheric aerosols, the Laboratory for Aerosols, Clouds and Optics (LACO) at the University of Maryland, Baltimore County (UMBC) has developed a novel instrument concept called the Imaging Nephelometer (Dolgos and Martins, 2014). The imaging nephelometer design, first realized in the PI-Neph, uses a wide field of view charge coupled device (CCD) camera to image the light scattered by aerosols in the path of a high-powered continuous wave laser. This setup permits the construction of an instrument that is compact and stable enough to be flown on a variety of airborne platforms, while still allowing for measurements of scattering matrix elements over an angular resolution and range that is comparable to state of the art laboratory techniques (Muñoz et al., 2011).

A detailed schematic of the PI-Neph design is shown in Fig. 1. The aerosol sample inside the PI-Neph is illuminated sequentially by a three-wavelength laser system operating at 473,532 and $671 \mathrm{~nm}$. The three beams are aligned by a system of dichroics and mirrors before having their polarization state precisely oriented by a Glan-Taylor linear polarizer. A liquid crystal variable retarder (LCVR) and Fresnel rhomb are then used to actively rotate the polarization state of laser light. After exiting the rhomb, the beam is guided by two mirrors, through a window into a $10 \mathrm{~L}$ sealed chamber containing the aerosol sample. The laser light traverses the length of the chamber before a corner cube retroreflector redirects the beam back into a beam trap adjacent to the entry window. The light scattered by the aerosol and surrounding gas is then imaged twice by the CCD camera, once for each of two roughly orthogonal linear polarization states of the laser.

If the scattering medium is assumed to be macroscopically isotropic and symmetric, then the scattering matrix elements $F_{13}$ and $F_{14}$ do not contribute to the total scattered signal and the resulting pair of image intensities depend only on the first two scattering matrix elements. The images can then be processed in a manner that allows for direct measurements of both the absolute phase function $F_{11}(\theta)$ as well as $F_{12}(\theta)$, with $\theta$ representing the zenith scattering angle (azimuthal symmetry is implied by the assumption of a macroscopically isotopic and symmetric medium). Measurements of molecular scatterers $\left(\mathrm{CO}_{2}\right.$ and $\left.\mathrm{N}_{2}\right)$ with absolute scattering matrix elements that are well characterized (Anderson et al., 1996; Young, 1980) allow for the determination of unique calibration constants for each angle. This angular-dependent absolute calibration allows for direct measurements of absolute phase function in known units $\left(\mathrm{Mm}^{-1} \mathrm{sr}^{-1}\right)$, free from any truncation error. The final products are then reported at standard temperature and pressure, with the Rayleigh scattering contribution from the surrounding gas subtracted. Additionally, normalized phases functions are represented by $\widetilde{F}_{11}$ in this paper and are scaled such that $\widetilde{F}_{11}\left(30^{\circ}\right)=1$.

The angular resolution of the measurement is limited by the spatial resolution of the CCD camera, the size of the cam-

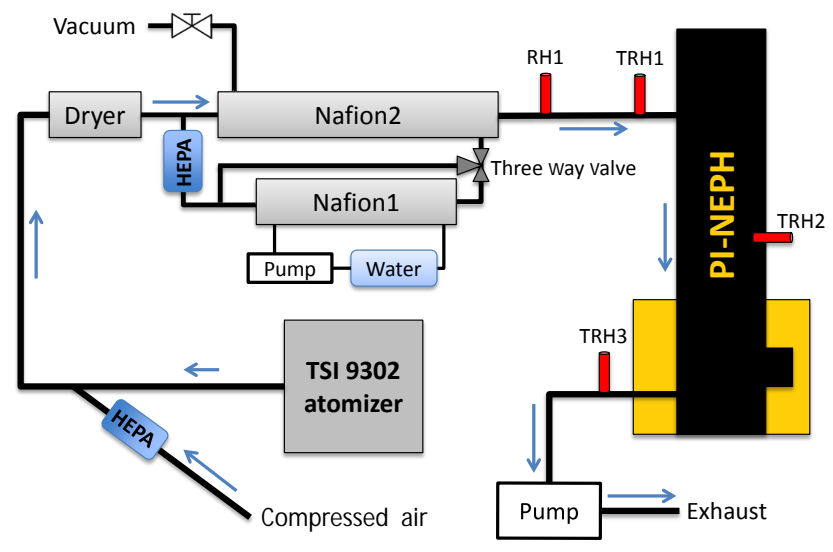

Figure 2. Laboratory aerosol generation instrumental setup used to suspend salts and PSL spheres.

era's aperture and the width of the laser beam. The resulting raw resolution typically varies as a function of scattering angle $\left(0.1^{\circ}<\mathrm{d} \theta<1^{\circ}\right)$ but the final results are always binned to one degree. The angular range of the instrument is limited by stray light emanating from the entry and exit points of the laser beam. In the PI-Neph, an angular range of 3 to $177^{\circ}$ in zenith scattering angle is frequently achieved.

PI-Neph measurements have been validated by a variety of methods since the instrument's completion in the summer of 2011. Measurements of monodisperse PSL spheres have yielded results that are in excellent agreement with Mie theory, while scattering coefficient measurements made in parallel with commercially available integrating nephelometers have agreed to within $5 \%$. A detailed summary of PI-Neph design, calibration and validation can be found in Dolgos and Martins (2014).

\subsection{Artificial aerosol generation}

Ammonium sulfate $\left(\left(\mathrm{NH}_{4}\right)_{2} \mathrm{SO}_{4}\right)$, ammonium nitrate $\left(\mathrm{NH}_{4} \mathrm{NO}_{3}\right)$ and sodium chloride $(\mathrm{NaCl})$ were suspended and humidified in a laboratory setting. Figure 2 displays a schematic diagram of the particle generation and measurement setup. The salts were diluted with distilled water to a concentration of $5 \mathrm{~g} \mathrm{~L}^{-1}$ before being agitated with an ultrasonic vibrator and later suspended using a single jet atomizer (TSI, model 9302). The generated aerosol was diluted with filtered compressed air before being fed into a dryer and then a humidifier. In the first stage, generated particles are dried, without heating, to a relative humidity less than $30 \%$ using a Perma Pure Nafion dryer. The dry particles are later humidified to a $\mathrm{RH}>80 \%$ using two Perma Pure Nafion humidifiers (Nafion1 and Nafion2). The humidifier and dryer consist of a Nafion membrane tubing that transfers moisture to or from the surrounding medium. The drier uses compressed air while the air passing through Nafion 1 is humidified by flowing water and then 


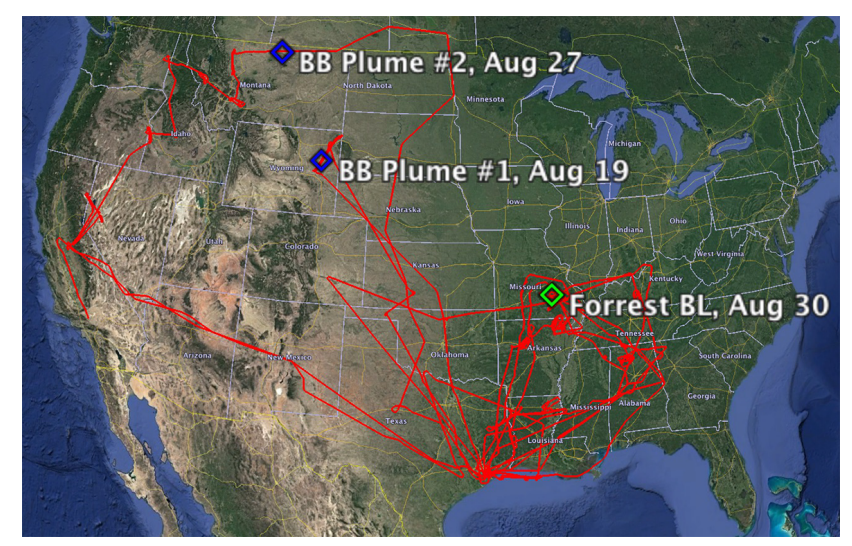

Figure 3. Flight paths of the $10 \mathrm{SEAC}^{4} \mathrm{RS}$ flights from which data are used in this paper. Additionally, three specific case studies are called out with diamonds. The case studies include two biomassburning-dominated aerosols (blue) as well as measurements made in the boundary layer of a forested region in southeastern Missouri (green).

used to humidify the sample passing though Nafion 2 . The separation of liquid water from the Nafion tube in contact with the aerosol sample allows for subtler control of the final relative humidity (Orozco et al., 2016). Angular scattering measurements of the aerosol were then made by the PI-Neph before the sample was discharged from the system.

The humidification system was set to relative humidity values above the deliquescence points of each salt solution, typically to an RH just over $80 \%$. The humidity was continuously monitored throughout the measurement using $\mathrm{RH}$ sensors located at the PI-Neph's inlet, measurement chamber and outlet. The stability and reproducibility of the particle generation was independently validated by the proper observation of deliquescence of different salts using an integrating nephelometer (model 3563, TSI Inc., St. Paul, MN, USA).

This setup was also used to suspend $903 \mathrm{~nm}$ diameter monodisperse PSL spheres (Nanosphere 3900A, ThermoFisher Scientific, Fremont, CA, USA), and scattering measurements of these spheres were made by the PI-Neph at low relative humidities $(\mathrm{RH}<20 \%)$. These measurements provide an opportunity to test the retrieval technique on an aerosol with a monodisperse size distribution and a refractive index that is very well characterized. The PSL generation and measurements also allowed for a small, subdegree realignment of the PI-Neph scattering angle calibration in the case of the salt measurements. This correction was not applied to the data used in the PSL retrievals to avoid biasing the result.

\subsection{Ambient measurements}

In addition to the laboratory measurements, inversions were performed on airborne data from the SEAC ${ }^{4} \mathrm{RS}$ experiment. SEAC ${ }^{4} \mathrm{RS}$ was a large field mission, that took place primarily over the continental United States in August and September of 2013. Over the course of the experiment three aircraft flew 54 different instruments on a total of 57 flights in an effort to understand a broad range of atmospheric phenomenon. A detailed description of the scientific goals, aircraft and instrumentation, as well as the corresponding implementation can be found in Toon et al. (2016).

The PI-Neph made measurements aboard the NASA DC-8 aircraft during $\mathrm{SEAC}^{4} \mathrm{RS}$. Ambient air was provided to the instrument through the NASA Langley Aerosol Research Group Experiment's (LARGE) shrouded diffuser inlet (McNaughton et al., 2007), which sampled isokinetically. A flow of $20 \mathrm{~L} \mathrm{~min}^{-1}$ was maintained through the PI-Neph's $10 \mathrm{~L}$ sample chamber, leading to an aerosol exchange time of the order of $30 \mathrm{~s}$. The raw sampling rate of the instrument was synchronized to match this interval, but the retrievals in this work are generally performed on time averages taken over a period of several minutes. The sample was conditioned with a temperature-controlled drier that heated the incoming ambient air to a temperature of $35^{\circ} \mathrm{C}$ and, in almost all cases, kept the relative humidity of the sample below $40 \%$.

In addition to PI-Neph scattering measurements, the LARGE group made comprehensive in situ measurements of aerosol properties in parallel to the PI-Neph. These measurements, containing data on particle number density, size distribution and optical properties, are a valuable resource for the intercomparison of PI-Neph measurements and the corresponding retrieved microphysical properties. In this work, size distributions retrieved from PI-Neph data will be compared extensively to measurements made by two dedicated optical particle size spectrometers (LAS model 3340, TSI Inc., St. Paul, MN, USA and model UHSAS, Droplet Measurement Technologies, Boulder, CO, USA) as well as an aerodynamic particle sizer (APS model 3321, TSI Inc., St. Paul, MN, USA). The two optical particle spectrometers also measured at low relative humidities during $\mathrm{SEAC}^{4} \mathrm{RS}$, but their sample was conditioned through a drier. This approach minimizes the evaporation of volatile compounds but can also lead to size-dependent losses in the aerosol when the instrument requires relatively large flow rates, as is the case for the PI-Neph. The aerodynamic particle sizer measurements were made at ambient humidities, but the ambient $\mathrm{RH}$ was determined to be less than $40 \%$ in all cases shown here so differences in PSD resulting from hygroscopic growth are not expected.

Fifty separate sampling periods, occurring over the course of 10 different flights, are highlighted in this work. The flights selected represent the 10 days with the highest quality PI-Neph data, for which data are available for at least one of LARGE's dedicated particle sizers. The intervals containing the highest aerosol-scattering levels during these flights were identified and a robust averaging procedure (Beaton and Tukey, 1974) was applied to periods for which no detectable changes in the normalized angular scattering data were observed. The total scattering for these averages ranged from 30 to just over $500 \mathrm{Mm}^{-1}$, with a median value of $90 \mathrm{Mm}^{-1}$. 
The resulting data set represents a wide range of aerosols, including urban pollution, organics and Saharan dust, and in over a dozen cases is dominated by biomass-burning (BB) emissions with transport ages ranging from hours to several days.

Additionally, three individual case studies were selected to provide detailed examples of PI-Neph measurements, the corresponding GRASP fits and the resulting retrieved size distributions. Two of these cases come from periods where the scattering signal was dominated by forest fire emissions, and were chosen to emphasize the subtle distinctions in angular scattering patterns that can occur, even between two aerosols of similar type. The third case consists of boundary layer (BL) measurements made over a heavily forested region of southeastern Missouri. This case represents one of only a couple of periods in which a significant coarse mode was observed. The sampling locations of these three cases, as well as the flight paths for the 10 selected flights, are shown in Fig. 3.

\subsection{Implementation of GRASP retrieval}

GRASP is a versatile software package capable of retrieving a wide range of atmospheric and surface properties from a variety of data sets. The GRASP algorithm and corresponding software builds on the successful heritage of the PARASOL (Dubovik et al., 2011), AERONET (Dubovik and King, 2000) and laboratory (Dubovik et al., 2006) retrievals.

GRASP's base aerosol model contains very few assumptions in comparison with traditional in situ or remote sensing retrieval algorithms. It includes all necessary components required to simulate a diverse range of atmospheric observations, including remote sensing (both suborbital and spacebased), optical in situ and laboratory measurements. The settings of the retrieved characteristics can be flexibly adjusted to match the particular application. For example, aerosol size distribution can be represented as a superposition of several lognormal functions or as a binned continuous function with different size resolutions (it is defined in nodal points).

As an inversion concept, GRASP implements Multi-Term Least Square fitting (Dubovik, 2004). This approach allows for convenient combining of different types of observations and multiple a priori constraints in a single inversion. For example, following this concept the AERONET retrieval (Dubovik and King, 2000) retrieves many parameters simultaneously: aerosol size distribution, spectral complex refractive index and fraction of spherical particles. A priori constraints on all functions (size distribution and all spectral dependencies) are assumed to be smooth, while a priori estimates of values are also used for some parameters. Moreover, using the same strategy, a statistically optimized multipixel retrieval concept was realized as an option in GRASP (Dubovik et al., 2011). This concept uses additional a priori knowledge about time and space variability of the retrieved
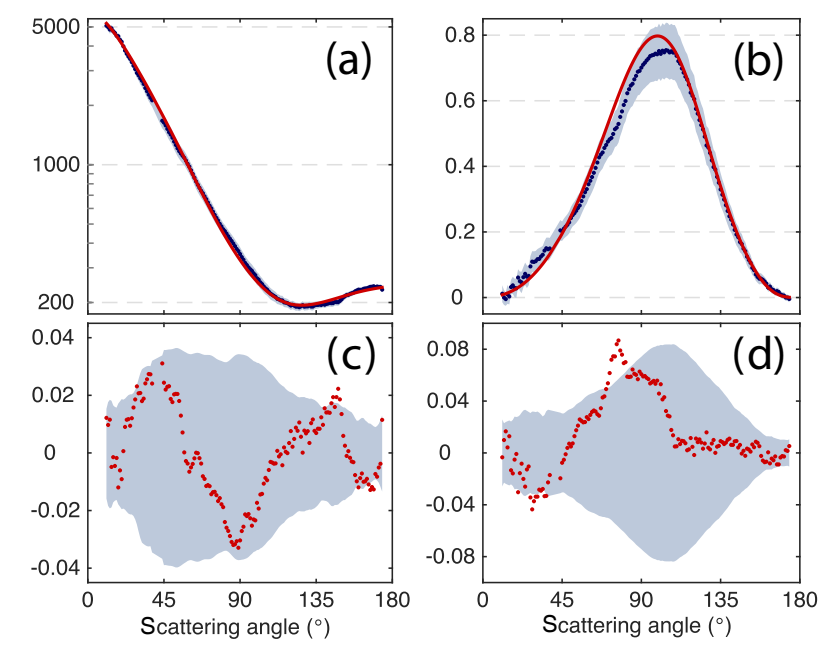

Figure 4. PI-Neph measurements at $532 \mathrm{~nm}$ (points) with $2 \sigma$ instrumental error (gray fill) and the GRASP retrieval best fit (solid line) for ammonium sulfate measurements made in the laboratory. (a) shows absolute $F_{11}\left(\mathrm{Mm}^{-1} \mathrm{sr}^{-1}\right)$ data plotted on a log scale, while (b) shows $-F_{12} / F_{11}$ data on a linear scale. (c) shows the $F_{11}$ differences according to the log transformation described in Eq. (1), while the conventional residuals in $-F_{12} / F_{11}$, as given by Eq. (2), are plotted in (d).

parameters in the inversion of coordinated observations (i.e., satellite observations in different pixels).

The flexibility built into the design of GRASP allows the user to select the assumptions that best match the information content of a particular data set. Moreover, while all of the above features have never been used in one single application, they often provide important potential for evolution of each application, for example via implementing synergy retrievals using a combination of different observations. The GRASP algorithm has previously been successfully applied to both satellite and ground-based upward-looking sky radiance measurements (Dubovik et al., 2011, 2014; Xu et al., 2016), while this paper represents the first application of GRASP to polar nephelometer data.

In this work GRASP size distributions were modeled with 16 logarithmically spaced size bins, generally ranging from $50 \mathrm{~nm}$ to $2.94 \mu \mathrm{m}$ in radius. The lower end of this range corresponds to the sensitivity limit of ensemble-type lightscattering measurements, given realistic particle size distributions. The upper bound was chosen to include the vast majority of coarse-mode particles capable of passing through the LARGE inlet, which has a $50 \%$ passing efficiency at an aerodynamic radius of $1.8 \mu \mathrm{m}$ (McNaughton et al., 2007). This size range was reduced to radii between 425 and $476 \mathrm{~nm}$ in the case of the PSL spheres, in order to better capture the fine structure of their very narrow size distribution. In all retrievals the shape of the size distribution is only constrained by a smoothness parameter and no assumptions about the number of modes are made. 

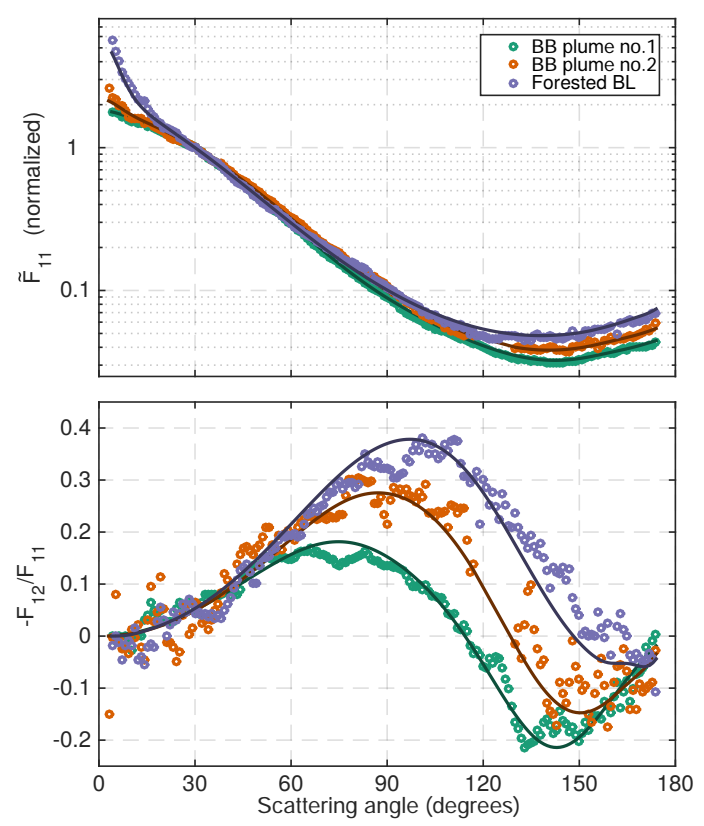

Figure 5. Normalized scattering matrix elements (circles) measured by the PI-Neph at $532 \mathrm{~nm}$ and the corresponding GRASP fits (solid lines) for the three highlighted SEAC ${ }^{4} \mathrm{RS}$ aerosol samples.

The search space for the real part of the refractive in$\operatorname{dex}(n)$ is semi-continuous between 1.33 and 1.68, while the imaginary part $(k)$ can range from 0 to $10^{-1}$. The refractive index is held constant with respect to size but is allowed to vary as a function of wavelength. GRASP assumes the aerosol is made up of a mixture of spheres and spheroids. The spheroid component has an axis ratio distribution that is fixed and is derived from feldspar measurements made by Volten et al. (2001). It can be shown that small deviations in the spheroid component's axis ratio distribution produces negligible changes in the angular dependence of the scattered light (Dubovik et al., 2006). It is therefore believed that this fixed shape distribution is capable of accurately modeling a wide range of nonspherical aerosols. The spheroid component was omitted from the PSL retrievals due to the computational demands associated with generating the required precomputed kernels for the finer size parameter grid spacing.

\section{Retrieval results and discussion}

\subsection{Measured data and retrieval fit}

In both the 50 selected SEAC ${ }^{4} \mathrm{RS}$ cases and in the laboratory measurements, the residuals between the GRASP fits and the PI-Neph measured values are generally within the PI-Neph instrumental error. Figure 4 shows the measured and fit $F_{11}$ and $-F_{12} / F_{11}$ for the ammonium sulfate case, and is typical of the bulk of the retrievals performed in this work. The residuals are also plotted to clearly emphasize the differences between the measurement and fit relative to the instrument's $2 \sigma$ error. In the case of the $F_{11}$ data the distances between the fit and measured values are reported as

$\operatorname{RES}_{F_{11}}=\log _{10}\left(F_{11}^{\mathrm{MEAS}}\right)-\log _{10}\left(F_{11}^{\mathrm{FIT}}\right)$,

with the PI-Neph error transformed accordingly. This transformation provides a measure of relative (as opposed to absolute) error, and provides a consistently sized metric across the 2 orders of magnitude covered by $F_{11}$. The separation in $-F_{12} / F_{11}$ data is represented simply as the difference between the measured and fit values.

$\operatorname{RES}_{F_{12} / F_{11}}=\left(\frac{F_{12}}{F_{11}}\right)^{\mathrm{FIT}}-\left(\frac{F_{12}}{F_{11}}\right)^{\mathrm{MEAS}}$

Figure 5 shows the normalized scattering matrix elements at $532 \mathrm{~nm}$ for the three selected SEAC ${ }^{4} \mathrm{RS}$ case studies. A strong forward peak can be seen in the forest boundary layer measurements, which is in accordance with the significant coarse mode observed by the aerodynamic and optical particle sizers. The two biomass-burning cases display very similar $F_{11}$ values, with the only significant difference being slightly enhanced forward and backward scattering in BB plume \#2. These subtle differences are likely to be driven by the slightly larger fraction of coarse-mode particles present in the latter case. In contrast to $F_{11},-F_{12} / F_{11}$ shows significant differences between the two biomass burning cases. The reduced magnitude of $-F_{12} / F_{11}$ in BB plume \#1 is likely driven primarily by differences in real refractive index between the two samples. This hypothesis is supported by simulations with a Mie code (Mishchenko et al., 2002) which demonstrated that, in the relevant size regime, changes in the refractive index of the order of 0.03 had little effect on $F_{11}$ but could easily change the ratio of $F_{12}$ to $F_{11}$ by $20 \%$ or more. It is this effect, in combination with the small median size of the fine mode, that produces the highest degree of linear polarization of the three samples in the forested boundary layer case.

The spectral dependence of $F_{11}$ and $-F_{12} / F_{11}$ for the biomass burning case study sampled on 19 August is shown in Fig. 6. The absolute phase function values are shown here to emphasize the additional information present in the spectral dependence of the scattering intensities. It should be noted that there is also significant spectral dependence in the shape of the scattering matrix elements, particularly in $-F_{12} / F_{11}$. These difference are driven primarily by changes in size parameter, but also result in some part from a nonzero spectral dependence of the complex refractive index. The same variables are plotted for the forested boundary layer case in Fig. 7 to show the spectral dependence of the measured scattering matrix elements and the corresponding fits when a significant coarse mode is present. In this last case, low aerosol concentrations and greater than average stray light levels inside the instrument resulted in a gap in the $473 \mathrm{~nm} F_{12}$ measurements between 80 and $142^{\circ}$ in scattering angle. 

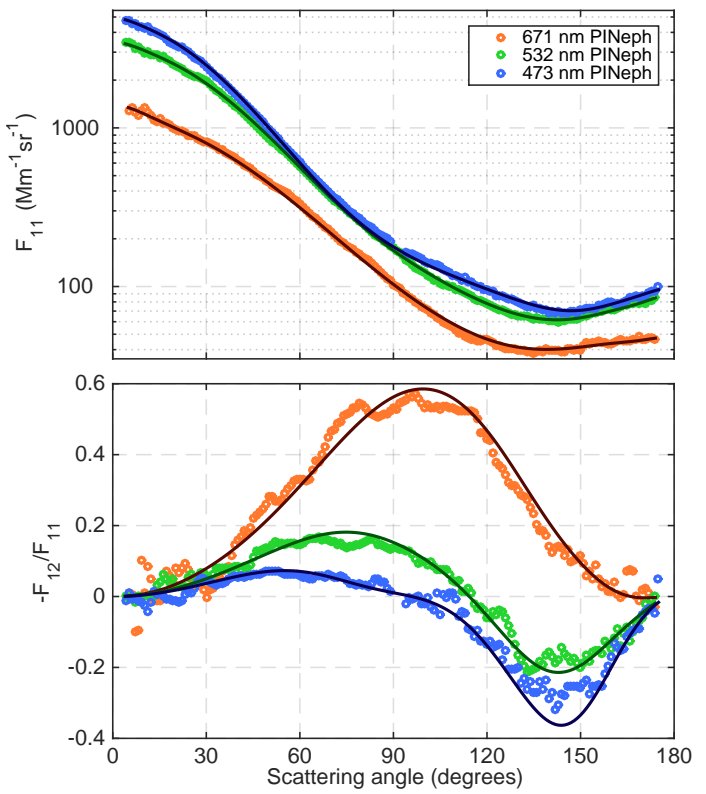

Figure 6. Scattering matrix elements at $473 \mathrm{~nm}$ (blue), $532 \mathrm{~nm}$ (green) and $671 \mathrm{~nm}$ (red) measured in BB plume \#1 on 19 August along with the corresponding GRASP fits (solid lines).

In the case of the polydisperse samples, the oscillations occasionally present in the data over angular scales of roughly 10 degrees are likely nonphysical, and are artifacts of insufficient sampling statistics in the coarse mode. The extended length of the imaging nephelometer sample volume makes it especially susceptible to sampling statistic artifacts that are produced by the largest particles. These particles make up a very small fraction of the total number concentration while simultaneously accounting for a disproportionately large portion of the total scattered light. This is especially apparent in the measurements of $-F_{12} / F_{11}$ as these values are closely related to the differences between sequential measurements at different polarizations. A large particle that is present at a given location in one image, but not present in the corresponding adjacent image will produce a significant artifact. The effect is also evident at low scattering angles, where larger particles tend to represent a larger portion of total scattering.

The monodisperse PSL measurements and corresponding GRASP fits (shown in Fig. 8) agree well in the case of $F_{11}$. Overall there is also good agreement in the $-F_{12} / F_{11}$ data, but some significant deviations do occur. The GRASP size distribution retrieval for this case had a full width, 67 percentile (FW67) of $17 \mathrm{~nm}$, which is more than twice the width specified by the manufacturer $(\mathrm{FW} 67=8.2 \mathrm{~nm}$ ). However, a narrower size distribution corresponding to the manufacturer's specification was found to reproduce some features of the measurement significantly better than GRASP's original retrieval. This improvement was most apparent in the 473 and $532 \mathrm{~nm}-F_{12} / F_{11}$ data, particularly at scattering angles
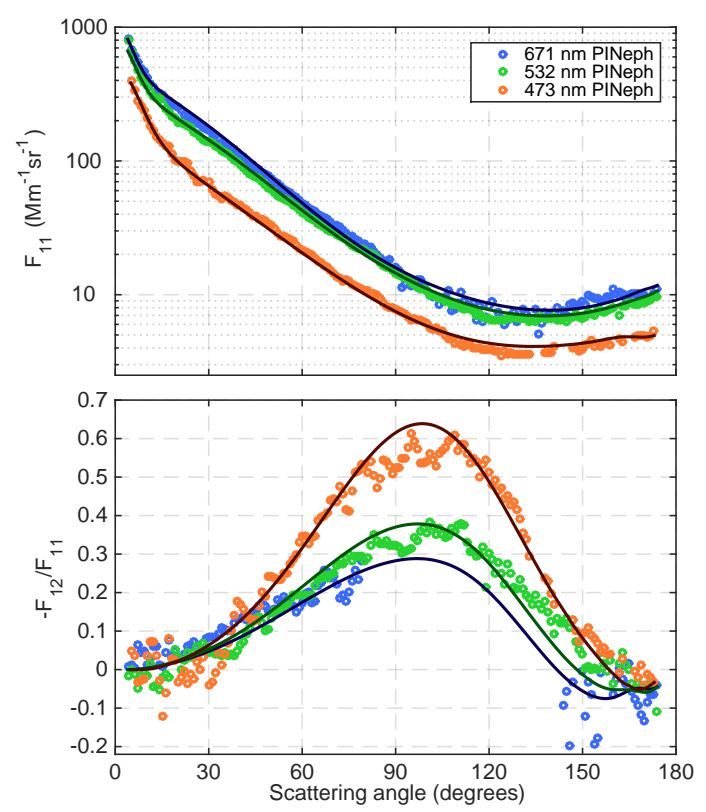

Figure 7. Scattering matrix elements at $473 \mathrm{~nm}$ (blue), $532 \mathrm{~nm}$ (green) and $671 \mathrm{~nm}$ (red) measured over a forested region of southeastern Missouri along with the corresponding GRASP fits (solid lines).

between 20 and $60^{\circ}$ where Mie theory predicts $-F_{12} / F_{11}$ to have high sensitivity to the distribution's width. Further studies indicated that GRASP was able to reproduce $-F_{12} / F_{11}$ corresponding to this narrower PSD with high accuracy when noise-free synthetic data were used as input. Additionally, running retrievals on the measured data using increasingly finer size resolution kernels did not improve the retrieval's ability to fit these features. The deviations in the fit were thus determined to be the result of GRASP's sensitivity to certain characteristics of the noise in the measured data, not insufficient size resolution in the fine-resolution kernels used in the PSL case.

\subsection{Refractive index retrievals}

Crystalline particles do not take on water until reaching relative humidities above their deliquescence point, generally around $80 \%$ in the case of salts. A range of methods are available for calculating the size of a given salt droplet after the transformation to an aqueous state has been made. In this work we choose the parameterization proposed by Petters and Kreidenweis (2007) for its simplicity and because the required $\kappa$ parameters are well known for the salts in question. This method states that $\mathrm{gf}_{\mathrm{vol}}$, the volume growth factor of a particle, can be estimated as

$\mathrm{gf}_{\mathrm{vol}}(\mathrm{RH})=1+\kappa \frac{\mathrm{RH}}{1-\mathrm{RH}}$, 
Table 1. Predicted and retrieved real refractive indices, median radii in volume and spherical fractions for the three artificially generated aerosols. Also shown are the deliquescence relative humidities (DRH), $\kappa$ values, and dry real refractive indices taken from the literature. All refractive indices are at $532 \mathrm{~nm}$.

\begin{tabular}{lrrrrrrrr}
\hline Compound & $\begin{array}{r}\text { DRH } \\
(\%)\end{array}$ & $\begin{array}{r}\text { Measured RH } \\
(\%)\end{array}$ & $\kappa$ & $\begin{array}{r}r_{50}^{\text {GRASP }} \\
(\mathrm{nm})\end{array}$ & $\begin{array}{r}\text { Sphere } \\
(\%)\end{array}$ & $n_{\text {dry }}$ & $n_{\text {wet }}^{\text {GRASP }}$ & $n_{\text {wet }}^{\kappa \text { Köhler }}$ \\
\hline $\mathrm{NaCl}$ & 80 & $83.7 \pm 2$ & $0.91-1.33$ & 144 & 100 & 1.544 & 1.395 & $1.353-1.372$ \\
$\left(\mathrm{NH}_{4}\right)_{2} \mathrm{SO}_{4}$ & 75 & $82.6 \pm 2$ & $0.33-0.72$ & 120 & 100 & 1.530 & 1.383 & $1.370-1.414$ \\
$\mathrm{NH}_{4} \mathrm{NO}_{3}$ & 62 & $83.5 \pm 2$ & $0.58-0.75$ & 129 & 54 & 1.554 & 1.392 & $1.371-1.393$ \\
\hline
\end{tabular}

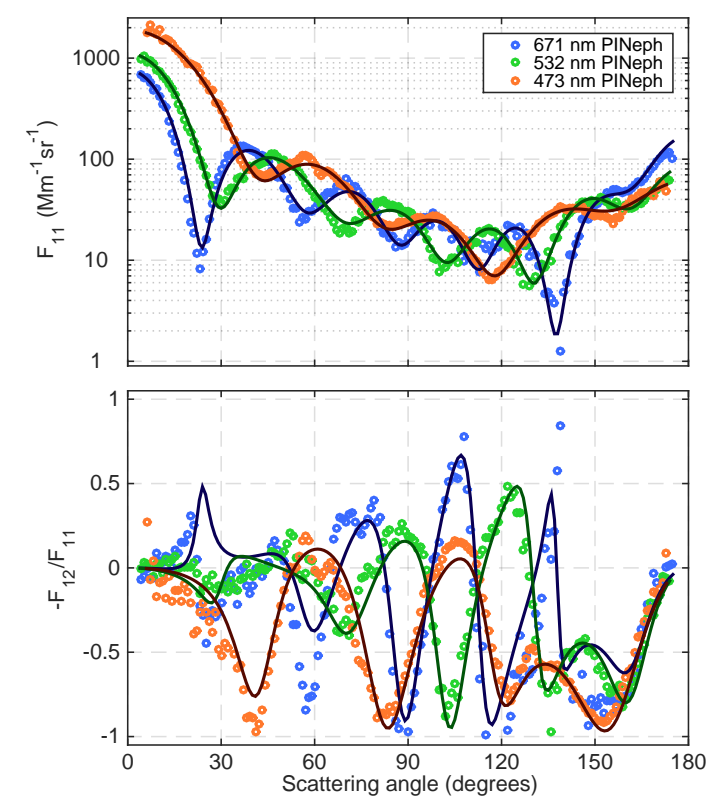

Figure 8. Scattering matrix elements at $473 \mathrm{~nm}$ (blue), $532 \mathrm{~nm}$ (green) and $671 \mathrm{~nm}$ (red) for $903 \mathrm{~nm}$ diameter PSL sample along with the corresponding GRASP fits (solid lines).

where $\mathrm{RH}$ is the relative humidity of the air surrounding the droplet and $\kappa$ is a constant that is determined by the composition of the particle in question.

The dry (crystalline) refractive indices of all three salts studied in this work are well known (Tang, 1996) and the resulting wet refractive index can be calculated from the volume mixing rule:

$n_{\text {wet }}(\mathrm{RH})=\frac{\left(\mathrm{gf}_{\mathrm{vol}}-1\right) n_{\mathrm{H}_{2} \mathrm{O}}+n_{\mathrm{dry}}}{\mathrm{gf}_{\mathrm{vol}}}$,

where $n_{\mathrm{H}_{2} \mathrm{O}}$ is the refractive index of water, $n_{\text {dry }}$ is the refractive index of the dry salt and $n_{\text {wet }}$ is the refractive index of the solution (Nessler et al., 2005). Alternative methods for estimating the refractive index of hygroscopic particles exist, but their deviation from the volume mixing rule is less than $1 \%$ for solutions that are made up of more than $50 \%$ water (Erlick et al., 2011; Schuster et al., 2009).
The refractive indices predicted from Eqs. (3) and (4) are compared with the corresponding GRASP retrievals in Table 1 . The ranges of $\kappa$ values given for sodium chloride and ammonium sulfate are taken from Table 3 of Koehler et al. (2006) and were derived from hygroscopic growth factors in the subsaturated domain. The $\kappa$ range used for ammonium nitrate are derived from measurements of cloud condensation nuclei $(\mathrm{CCN})$ at supersaturations less than $1 \%$, and originate from Svenningsson et al. (2006), with the spread representing an uncertainty of 1 standard deviation. Growth-factorderived $\kappa$ values were not available for ammonium nitrate but the difference between growth factor and $\mathrm{CCN}$-derived $\kappa$ values is generally small compared to the uncertainty in $\kappa$ resulting from measurement errors (Petters and Kreidenweis, 2007). The range in the final predicted wet refractive indices results from the bounds on the $\kappa$ values, as well as a $2 \%$ uncertainty in the RH measurement made inside the PI-Neph.

The retrieved refractive index values are in good agreement with the range predicted by $\kappa$-Köhler theory and the existing literature. Sensitivity studies, performed on ensembles of synthetic data perturbed with modeled PI-Neph noise, suggest uncertainties of 1 standard deviation in retrieved real refractive indices of around 0.02 for nonabsorbing particles in the size range of these humidified salts. These studies also showed a general trend of increasing accuracy in the retrieved real part of the refractive index as the median radius of the particles increased. The converse was true for absorption, where more absorbing particles tended to produce more error in the real refractive index inversion. The agreement between the retrieved and predicted refractive index values is consistent with this error analysis.

The retrieved imaginary parts of the refractive index (not shown) of the ammonium nitrate and ammonium sulfate solutions were both found to be of the order of $10^{-3}$. These values are indicative of moderate absorption but are larger than more established values found in the existing literature, which suggests very little absorption $\left(k<10^{-7}\right)$ for all three of the solutions measured (Fenn et al., 1985; Toon and Pollack, 1976; Hale and Querry, 1973). An even higher imaginary part of the refractive index $(k=0.026)$ was retrieved in the case of the sodium chloride sample. The magnitude of this value may be, at least in part, related to an unrealistically high retrieved real refractive index. This hypothe- 


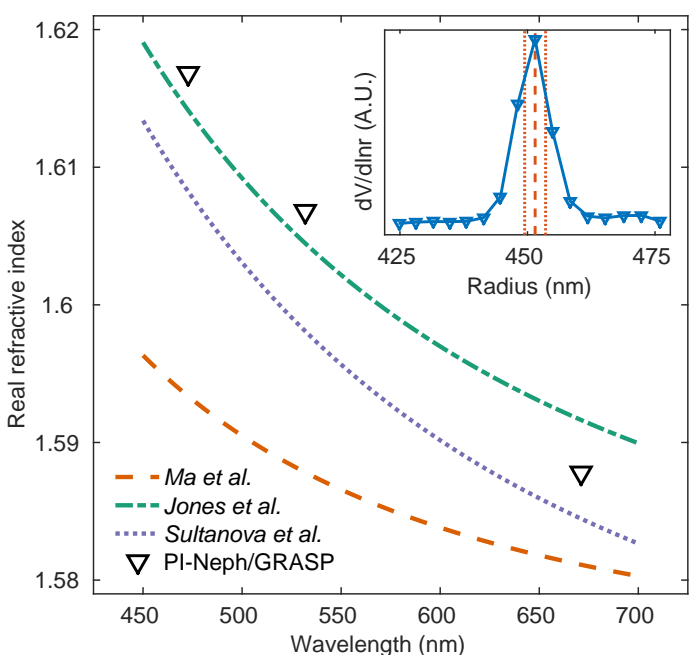

Figure 9. Retrieved real part of the refractive index for PSL spheres, alongside three previous, modern measurements of polystyrene refractive indices (Ma et al., 2003; Jones et al., 2013; Sultanova et al., 2003). The subplot shows the retrieved size distribution (blue) along side the manufacturer's specified central radius (red dashes) and FW67 (red dots).

sis is supported by the fact that constraining the retrieved real refractive index to the range predicted by the sample $\mathrm{RH}$ and $\kappa$-Köhler theory resulted in significantly lower retrieved values of sodium chloride absorption. A comparison was also made between the retrieved single-scattering albedo (SSA) and the SSA derived from Particle Soot/Absorption Photometer (PSAP, Radiance Research, Seattle, WA, USA) and integrated scattering measurements (Integrating Nephelometer 3563, TSI Inc., St. Paul, MN, USA) in SEAC ${ }^{4}$ RS. A statistically significant correlation between the two data sets was determined to exist, but the retrieved SSA was also found to systemically overestimate the measured absorption. Notice that the retrieval was based only on scattering measurements (no absorption or extinction data were included) and therefore is expected to show limited sensitivity to these variables. A detailed analysis of the sensitivity of the GRASP/PINeph retrieval to absorption is beyond the scope of this work.

After passing their deliquescence point, crystalline salt particles should transform into saline droplets and become spherical in shape. The GRASP/PI-Neph inversion was able to accurately reproduce this spherical morphology in the sodium chloride and ammonium sulfate case, but a spherical fraction of only $54 \%$ was retrieved for the ammonium nitrate sample. This deviation from expectation is likely driven by a combination of random error in the PI-Neph measurement and the fact that the scattering of nonspherical particles tends to deviate less from that of spherical particles as particle size decreases. This notion is confirmed in the sensitivity studies previously described, where it was found that there was very little sensitivity to sphericity in the case of small particles $(r<200 \mathrm{~nm})$.

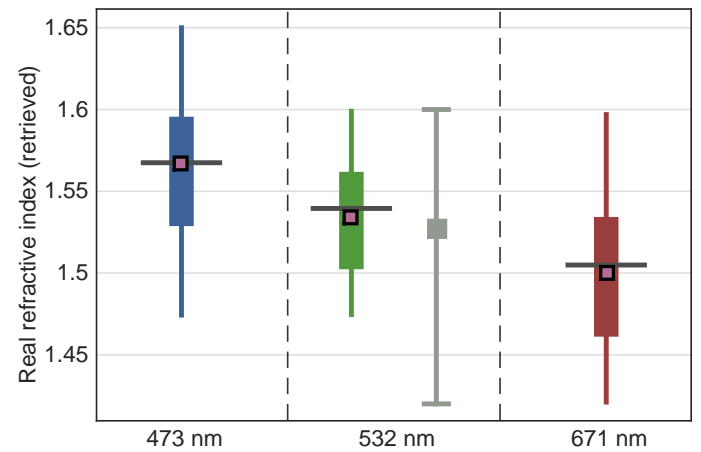

Figure 10. Retrieved refractive index at all three PI-Neph wavelengths for the 50 selected SEAC ${ }^{4} \mathrm{RS}$ samples. Box and whisker plots show the data distribution by quartile while the connected black squares show the spectral dependence of the mean. The gray bounds at $532 \mathrm{~nm}$ denote the minimum and maximum values measured by Shingler et al. (2016) in SEAC ${ }^{4} \mathrm{RS}$ while the gray square denotes the corresponding mean.

Retrievals of the monodisperse PSL spheres produced real refractive index values that were within the range of existing measurements available in the literature at all three wavelengths (Bateman et al., 1959; Ma et al., 2003; Sultanova et al., 2003; Jones et al., 2013). The spectral dependence of the retrieved values, as well as the three most recently reported Cauchy's equation parameterizations of PSL refractive index can be found in Fig. 9. The retrieved imaginary part of the refractive index for these spheres was of the order of $10^{-3}$ for all three wavelengths, slightly higher than the values of around $4 \times 10^{-4}$ that have been reported by more sensitive techniques (Bateman et al., 1959; Ma et al., 2003).

Figure 10 shows the spectrally dependent distribution of the retrieved dry refractive indices for the 50 chosen SEAC ${ }^{4} \mathrm{RS}$ cases. The mean retrieved real part of the refractive index at $532 \mathrm{~nm}$ for the 50 cases, composed primarily of biomass-burning and urban-biogenic mixtures, was found to be 1.53. This figure is in line with the existing measurements made under similar conditions (Shingler et al., 2016), but unfortunately very few airborne, in situ measurements of refractive index are available. Remote sensing retrievals of biomass-burning aerosol generally range from 1.47 to 1.55 (Dubovik et al., 2002; Li and Mao, 1990; Westphal and Toon, 1991; Yamasoe et al., 1998), while remote retrievals of urban pollution have generally yielded somewhat lower values, ranging from 1.39 to 1.46 (Dubovik et al., 2002; Redemann et al., 2000). These lower values observed in the urban-pollution remote sensing retrievals are likely driven in large part by particle hygroscopicity. The PI-Neph/GRASP retrievals of real refractive index are expected to be significantly higher in analogous cases as the PI-Neph measurements were made at very low relative humidities, where hygroscopic growth is virtually nonexistent. In spite of these differences in measurement conditions, as well as in the sam- 
Table 2. Truncation-corrected total scattering $\left(\beta_{\mathrm{sca}}\right)$ from the integrating nephelometer as well as the GRASP retrieval of real refractive index, sphere fraction and SSA for the three highlighted case studies. Additionally, the SSA derived from PSAP and integrating nephelometer measurements is shown for comparison. All spectrally dependent parameters are listed at $532 \mathrm{~nm}$.

\begin{tabular}{|c|c|c|c|c|c|c|c|}
\hline Aerosol case & Date & Time (UTC) & $\beta_{\text {sca }}$ & $m_{\text {GRASP }}$ & Sphere $_{\text {GRASP }}$ & $\mathrm{SSA}_{\mathrm{GRASP}}$ & SSAPSAP \\
\hline BB plume \#1 & 19 August & 19:06-19:13 & $489 \mathrm{Mm}^{-1}$ & 1.594 & $64.5 \%$ & 0.976 & 0.964 \\
\hline BB plume \#2 & 27 August & $21: 42-21: 48$ & $95.9 \mathrm{Mm}^{-1}$ & 1.565 & $91.0 \%$ & 0.962 & 0.959 \\
\hline Forested BL & 30 August & $20: 55-21: 12$ & $41.9 \mathrm{Mm}^{-1}$ & 1.566 & $53.9 \%$ & 0.908 & 0.930 \\
\hline
\end{tabular}

ple regions in question, the values are remarkably similar, especially in the case of biomass-burning emissions, where hygroscopic influences are expected to be much more limited. Additionally, the spectral dependence is in line with expectation and closely matches measurements of common natural aerosol constituents made by Hale and Querry (1973).

Table 2 shows details of the retrievals performed on the three cases studies. The retrieved real refractive index of the 19 August biomass-burning plume is slightly higher than the values reported in the literature, and represents the upper end of the values retrieved in the 50 selected samples. The other two cases also returned higher than average values, although they were more in line with the other samples and typical values reported in the existing literature. The biomass burning particles were also found to be less absorbing than that of typical smoke, but the values produced by GRASP are in good agreement with direct SSA measurements aboard the DC-8 derived from PSAP and integrating nephelometer measurements (SEAC4RS, 2015). A significant percentage of particles were determined to be nonspherical in these cases, especially the 19 August biomass-burning plume and 30 August forested boundary layer aerosols. The cases on 19 and 27 August are dominated by small particles, and in turn there are large uncertainties in the sphericity product. The low spherical percentage retrieved for the 30 August case is potentially realistic given the significance of the coarse mode, but additional independent measurements of sphericity are limited.

\subsection{Size distribution retrievals}

The size distribution retrieved for the PSL spheres is shown in the subpanel of Fig. 9 and agrees well with the manufacturer's specifications. The median diameter of the retrieved distribution was found to be $902.7 \mathrm{~nm}$ which shows excellent agreement with the manufacturer's NIST traceable specification of $903 \mathrm{~nm} \pm 12$. It is the authors' experience, based on PI-Neph measurement inversions on a range of PSL products from the same manufacturer, that the uncertainty listed often significantly overestimates the true uncertainty in the central diameter of the size distribution. As discussed in Sect. 3.1, the retrieval returned a distribution width that was approximately twice the value specified by the manufacturer but features in the $-F_{12} / F_{11}$ measurement indicate that the true width is more likely inline with the manufacturer's specification FW67 of $8.2 \mathrm{~nm}$. Similarly accurate results sizing PSL spheres with PI-Neph data are demonstrated in Dolgos and Martins (2014) through the use of a Mie theory lookup table.

The retrieved size distributions for all three SEAC ${ }^{4} \mathrm{RS}$ case studies are plotted alongside measurements made by dedicated particle sizers in Fig. 11. The APS data were converted from aerodynamic to geometric size using an assumed density of $1.3 \mathrm{~g} \mathrm{~cm}^{-3}$ and a shape factor of unity. Uncertainties in these assumptions can generate significant changes in the resulting geometric PSD, but the presence of APS data can still be used as an optically independent, qualitative confirmation regarding the presence of significant coarse mode. The UHSAS (Ultra-High Sensitivity Aerosol Spectrometer) data are shown for two different calibration aerosols, PSL spheres and ammonium sulfate, which have real refractive indices of 1.61 (Jones et al., 2013) and 1.53 (Tang, 1996) respectively. The LAS (Laser Aerosol Spectrometer) data shown correspond to calibration with PSL spheres.

In all three of these cases the peak of the fine mode generally occurs around a radius of $150 \mathrm{~nm}$. These values are typical of the majority of the 50 selected periods, all of which have fine mode median radii (in volume) between 100 and $200 \mathrm{~nm}$. The PI-Neph/GRASP PSD retrievals fall between the two different UHSAS calibrations in each of the three cases, which again is typical of almost all 50 samples.

Among the 50 selected periods for which size distribution comparisons were made, only two cases had coarse modes with volume concentrations that made up a significant portion of the total particle volume. The first of these cases, a sample dominated by transported Saharan dust, had very low aerosol loading and the bulk of the scattering matrix data at scattering angles above $40^{\circ}$ was below the PI-Neph's limit of detection. The second of these cases, the forested boundary layer measurements taken on 30 August, was therefore chosen as one of the three highlighted case studies. In both cases the size distributions agree remarkably well in the coarse mode, suggesting significant sensitivity to larger particles in the retrieved product. This sensitivity likely resulted primarily from the PI-Neph's ability to measure down to scattering angles as low as $3^{\circ}$ during $\operatorname{SEAC}^{4} \mathrm{RS}$. Lienert et al. (2003) was also able to show sensitivity to supermicron particles given a minimum scattering angle of around $2^{\circ}$. On the other hand, Sviridenkov et al. (2014) determined that single- 

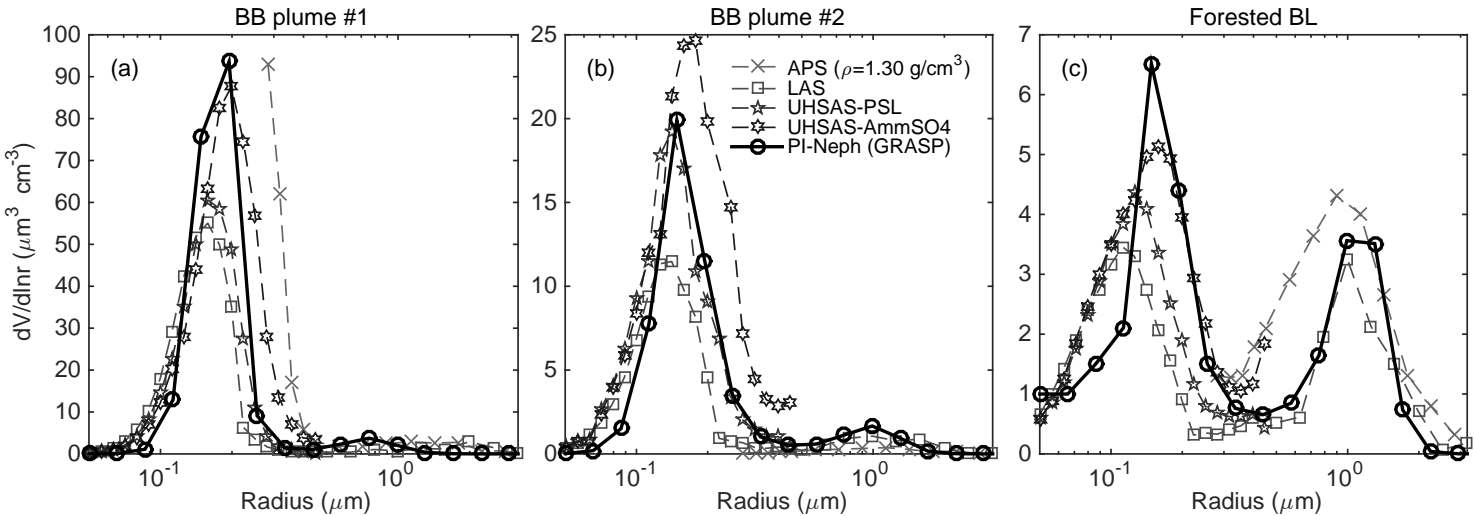

Figure 11. Direct comparisons of size distributions retrieved using GRASP with dedicated particles sizers that sampled in parallel to the PINeph. The three cases selected show measurements from the (a) 19 August and (b) 27 August biomass-burning cases, as well as (c) boundary layer measurements made above a forested region of southeastern Missouri on 30 August.
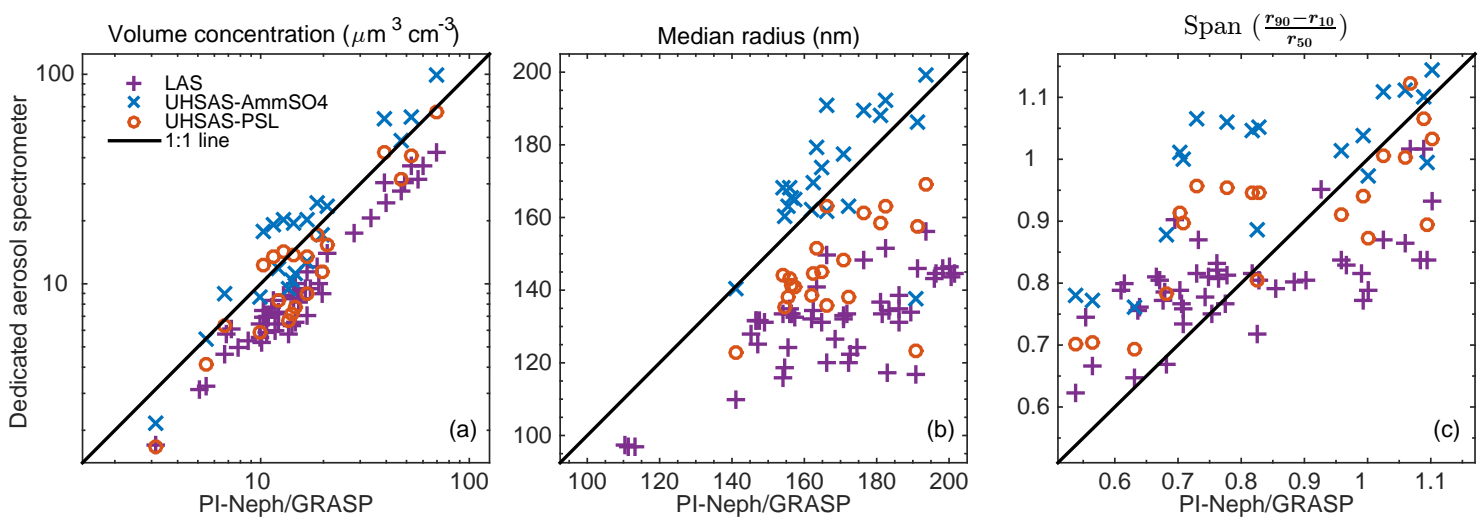

Figure 12. Scatter plot comparisons of retrieved size distributions with particle sizers sampling in parallel to the PI-Neph. In order from left to right the panels show total fine mode (a) volume concentration, (b) volume median radius and (c) span $=\frac{r_{90}-r_{10}}{r_{50}}$. The value retrieved from PI-Neph measurements is plotted on the horizontal axis while the value measured by the corresponding dedicated aerosol spectrometer is plotted along the vertical axis. The comparisons are made against LAS measurements (purple pluses), UHSAS ammonium-sulfate equivalent optical diameters (blue crosses) and UHSAS PSL equivalent optical diameters (red circles).

scattering measurements over a scattering angle range of 10 to $90^{\circ}$ were insufficient to provide significant information about the coarse mode. All of these conclusions are in agreement with theoretical sensitivity studies indicating that measurements at very low scattering angles are required if the coarse mode is to be accurately recovered (Dubovik et al., 2000).

In order to simplify the comparison of the retrieved size distributions with those measured by the dedicated aerosol spectrometers, the fine mode of each PSD was parameterized according to three metrics: total volume concentration, median radius and the span of the distribution. When determining these metrics, the values of the volume distributions corresponding to radii less than $50 \mathrm{~nm}$ were first removed, as this lower bound corresponds to the bottom of the PI-Neph/GRASP retrieval range. The upper end of the remaining size distribution was then further truncated to include only fine-mode particles. The division between the fine and coarse modes was defined as the minimum value of the LAS volume distribution, closest to $r=300 \mathrm{~nm}$. A visual inspection of all cases confirmed that this metric was sufficient to reasonably isolate the fine mode when two modes were present. The volume concentration, median $\left(r_{50}\right)$ and span $\left(\left(r_{90}-r_{10}\right) / r_{50}\right)$ were then calculated using theses final truncated volume distributions. Linear interpolation was used when the 10th, 50th or 90th percentile values, as well as the bounds of the truncated distributions, fell between the midpoints of two size bins. Scatter plots showing the results of these parameterizations for the three OPC measurements vs. the corresponding PI-Neph retrieval are shown in Fig. 12.

The retrieved volume concentrations and median radii generally fall somewhere between the two different UHSAS calibrations, with the best agreement generally tending towards the ammonium sulfate calibration. This is consistent with the average retrieved refractive index for the 50 cases $(n=1.53)$ which is in very close agreement to the dry re- 
fractive index of ammonium sulfate found in the literature. The LAS consistently measured smaller and fewer particles than all the other sizing techniques, but still showed significant correlation with the GRASP retrievals of PI-Neph measurements. There was weaker agreement regarding the width of the distribution among the four techniques. The retrieved spans generally best matched the corresponding PSLcalibrated UHSAS values, but the values covered a larger range of spans than the values measured by the OPCs. The spans retrieved from PI-Neph measurements fell between 0.55 and 1.03 in $95 \%$ of the cases. In contrast, the LAS showed the least variability in span, with $95 \%$ of the values falling between 0.65 and 0.85 . The differences in span between PI-Neph retrievals and the OPCs was likely driven in large part by their different sampling techniques (ensemble vs. single particle measurements).

The large differences between UHSAS measurements under different calibrations, with disparate refractive indices, demonstrates the significance of the refractive index assumptions required. The results of this work, as well as others (Shingler et al., 2016), suggest that the real refractive indices of natural aerosol can frequently reach values as low as 1.48 at $532 \mathrm{~nm}$. This is substantially lower than the refractive index of ammonium sulfate $(n=1.53)$, which has the lowest value of the aerosols that are commonly used to calibrate optical particle sizers, and further emphasizes the significance of the basis resulting from uncertainty in refractive indices.

In order to further asses the retrieval variability, resulting from changes in refractive index and sphericity, the 50 SEAC ${ }^{4} \mathrm{RS}$ cases were inverted a second time with assumptions corresponding to PSL spheres. In this analysis the complex refractive index was forced match measurements of PSL and nonspherical particles were excluded from GRASP's aerosol model. This configuration produced significantly better agreement with the PSL calibrated UHSAS measurements in volume concentration, median radius and span, when compared to the unconstrained retrievals. This result further demonstrates that differences in fundamental assumptions about the optical and morphological properties of the particles are driving a significant portion of the differences between the retrieved and measured values.

\section{Conclusions}

This work represents the first time that aerosol optical and microphysical properties were retrieved from airborne, polar nephelometer data. Additionally, the PI-Neph/GRASP inversion makes fewer assumptions regarding the shape of the recovered size distribution and particle sphericity than previous in situ light-scattering retrievals. The resulting products are in good agreement with the expectations, and compare well with existing measurement techniques. Furthermore, the GRASP fit to PI-Neph data is consistent with the PI-Neph's level of error, indicating that the assumptions made in the retrieval are sufficient to faithfully reproduce the light scattering of realistic, ambient aerosols.

The real refractive index of humidified salts retrieved with this method agree well with the predictions made by $\kappa$ Köhler theory and existing dry measurements. The PI-Neph retrieval of PSL refractive index agrees with other contemporary techniques to within the deviation present in those reported values. Furthermore, inversions of airborne SEAC ${ }^{4} \mathrm{RS}$ data produced refractive indices that were in good agreement with the existing literature.

There is significant spread in the aerosol size distribution measurements made by the OPCs, but the corresponding PINeph/GRASP retrievals generally fall within the range of the existing measurements. A major part of the differences in the measured size distributions stem from the need to assume a refractive index during the calibration process. The PI-Neph/GRASP retrieval has sufficient sensitivity to constrain the refractive index with enough accuracy to potentially reduce these biases. The fact that the PSD retrievals fell between the two UHSAS calibrations, in a manner consistent with the retrieved refractive index, supports this conclusion.

The PI-Neph inversions have also shown moderate sensitivity to absorption but a detailed assessment of the accuracy of this retrieved parameter is beyond the scope of this paper and will have to remain the subject of future study. Additionally, promising results were obtained regarding the retrieval of sphericity in the case of the humidified salts as well as in sensitivity studies, but as a result of the limited morphological information available in the $\mathrm{SEAC}^{4} \mathrm{RS}$ data set, a robust evaluation of this product is limited at this time.

\section{Code availability}

The GRASP software package is open-source and available for download by request at http://www.grasp-open.com.

\section{Data availability}

All relevant measurements made during the SEAC ${ }^{4} \mathrm{RS}$ experiment are available through the SEAC ${ }^{4} \mathrm{RS}$ data archive at http://www-air.larc.nasa.gov/missions/seac4rs/ (SEAC4RS, 2015). Requests for additional data can be made to the corresponding author at reedespinosa@umbc.edu.

Competing interests. The authors declare that they have no conflict of interest.

Acknowledgements. We acknowledge funding support from the NASA Earth Science Enterprise for the SEAC ${ }^{4} \mathrm{RS}$ campaign under Grant NNX12AC37G, and under the Atmospheric Composition Campaign Data Analysis and Modeling Program (ACCDAM) grant NNX14AP73G, both managed by Hal Maring. The authors would 
also like to thank the members of the LARGE group, particularly Bruce Anderson, Edward Winstead and Lee Thornhill for their support incorporating the PI-Neph into the LARGE instrument package. We are also grateful for the scientific and technical support of the LACO team at UMBC, especially Dominik Cieslak and Frank Harris. Additionally, we would like to thank the entire SEAC ${ }^{4} \mathrm{RS}$ science team for providing supporting data and relevant discussion.

Edited by: M. Wendisch

Reviewed by: two anonymous referees

\section{References}

Anderson, T. L., Covert, D. S., Marshall, S. F., Laucks, M. L., Charlson, R. J., Waggoner, A. P., Ogren, J. A., Caldow, R., Holm, R. L., Quant, F. R., Sem, G. J., Wiedensohler, A., Ahlquist, N. A., and Bates, T. S.: Performance Characteristics of a High-Sensitivity, Three-Wavelength Total Scattering/Backscatter Nephelometer, J. Atmos. Ocean. Tech., 13, 967-986, 1996.

Barkey, B., Paulson, S. E., and Chung, A.: Genetic Algorithm Inversion of Dual Polarization Polar Nephelometer Data to Determine Aerosol Refractive Index, Aerosol Sci. Technol., 41, 751-760, doi:10.1080/02786820701432640, 2007.

Barkey, B., Kim, H., and Paulson, S. E.: Genetic Algorithm Retrieval of Real Refractive Index from Aerosol Distributions that are not Lognormal, Aerosol Sci. Technol., 44, 1089-1095, doi:10.1080/02786826.2010.512025, 2010.

Bateman, J., Weneck, E., and Eshler, D.: Determination of particle size and concentration from spectrophotometric transmission, J. Coll. Sci. Imp. U. Tok., 14, 308-329, doi:10.1016/00958522(59)90055-8, 1959.

Beaton, A. E. and Tukey, J. W.: The Fitting of Power Series, Meaning Polynomials, Illustrated on Band-Spectroscopic Data, Technometrics, 16, 147-185, doi:10.2307/1267936, 1974.

Cai, Y., Montague, D. C., Mooiweer-Bryan, W., and Deshler, T.: Performance characteristics of the ultra high sensitivity aerosol spectrometer for particles between 55 and $800 \mathrm{~nm}$ : Laboratory and field studies, J. Aerosol Sci., 39, 759-769, doi:10.1016/j.jaerosci.2008.04.007, 2008.

Dolgos, G. and Martins, J. V.: Polarized Imaging Nephelometer for in situ airborne measurements of aerosol light scattering, Opt. Express, 22, 21972-21990, doi:10.1364/OE.22.021972, 2014.

Dubovik, O.: Optimization of Numerical Inversion in Photopolarimetric Remote Sensing, NATO Sci. Ser. II Math., 65-106, doi:10.1007/1-4020-2368-5_3, 2004.

Dubovik, O. and King, M.: A flexible inversion algorithm for retrieval of aerosol optical properties from Sun and sky radiance measurements, J. Geophys. Res., 105, 20673-20696, 2000.

Dubovik, O., Smirnov, A., Holben, B. N., King, M. D., Kaufman, Y. J., Eck, T. F., and Slutsker, I.: Accuracy assessments of aerosol optical properties retrieved from Aerosol Robotic Network (AERONET) Sun and sky radiance measurements, J. Geophys. Res.-Atmos., 105, 9791-9806, doi:10.1029/2000JD900040, 2000.

Dubovik, O., Holben, B., Eck, T., Smirnov, A., Kaufman, Y., and King, M.: Variability of absorption and optical properties of key aerosol types observed in worldwide locations, J. Atmos. Sci., 59, 590-608, 2002.

Dubovik, O., Sinyuk, A., Lapyonok, T., Holben, B. N., Mishchenko, M., Yang, P., Eck, T. F., Volten, H., Muñoz, O., Veihelmann, B., van der Zande, W. J., Leon, J.-F., Sorokin, M., and Slutsker, I.: Application of spheroid models to account for aerosol particle nonsphericity in remote sensing of desert dust, J. Geophys. Res., 111, D11208, doi:10.1029/2005JD006619, 2006.

Dubovik, O., Herman, M., Holdak, A., Lapyonok, T., Tanré, D., Deuzé, J. L., Ducos, F., Sinyuk, A., and Lopatin, A.: Statistically optimized inversion algorithm for enhanced retrieval of aerosol properties from spectral multi-angle polarimetric satellite observations, Atmos. Meas. Tech., 4, 975-1018, doi:10.5194/amt-4975-2011, 2011.

Dubovik, O., Lapyonok, T., Litvinov, P., Herman, M., Fuertes, D., Ducos, F., Torres, B., Derimian, Y., Huang, X., Lopatin, A., Chaikovsky, A., Aspetsberger, M., and Federspiel, C.: GRASP: a versatile algorithm for characterizing the atmosphere, SPIE Newsroom, 2-5, doi:10.1117/2.1201408.005558, 2014.

Eiden, R.: The elliptical polarization of light scattered by a volume of atmospheric air, Appl. Opt., 5, 569-75, 1966.

Erlick, C., Abbatt, J. P. D., and Rudich, Y.: How Different Calculations of the Refractive Index Affect Estimates of the Radiative Forcing Efficiency of Ammonium Sulfate Aerosols, J. Atmos. Sci., 68, 1845-1852, doi:10.1175/2011JAS3721.1, 2011.

Fenn, R. W., Clough, S. A., Gallery, W. O., Good, R. E., Kneizys, F. X., Mill, J., Rothman, L., Shettle, E., and Volz, F.: Optical and Infrared Properties of the Atmosphere, in: Handbook of Geophysics and the Space Environment, 18, NTIS, 1985.

Hale, G. M. and Querry, M. R.: Optical Constants of Water in the 200-nm to 200-microm Wavelength Region, Appl. Opt., 12, 555563, doi:10.1364/AO.12.000555, 1973.

Jones, M. R., Leong, K. H., Brewster, M. Q., and Curry, B. P.: Inversion of light-scattering measurements for particle size and optical constants: experimental study, Appl. Opt., 33, 4035-4041, doi:10.1364/AO.33.004035, 1994.

Jones, S. H., King, M. D., and Ward, A. D.: Determining the unique refractive index properties of solid polystyrene aerosol using broadband Mie scattering from optically trapped beads, Phys. Chem. Chem. Phys., 15, 20735-20741, doi:10.1039/c3cp53498g, 2013.

Koehler, K. A., Kreidenweis, S. M., DeMott, P. J., Prenni, A. J., Carrico, C. M., Ervens, B., and Feingold, G.: Water activity and activation diameters from hygroscopicity data - Part II: Application to organic species, Atmos. Chem. Phys., 6, 795-809, doi:10.5194/acp-6-795-2006, 2006.

Li, J. and Mao, J. T.: Properties of Atmospheric Aerosols Inverted from Optical Remote-Sensing, Atmos. Environ. A-Gen., 24, 2517-2522, 1990.

Lienert, B. R., Porter, J. N., and Sharma, S. K.: Aerosol size distribution from genetic inversion of polar nephelometer data, J. Atmos. Ocean. Tech., 20, 1403-1410, doi:10.1175/15200426(2003)020<1403:ASDFGI>2.0.CO;2, 2003.

Ma, X., Lu, J. Q., Brock, R. S., Jacobs, K. M., Yang, P., and Hu, X.-H.: Determination of complex refractive index of polystyrene microspheres from 370 to $1610 \mathrm{~nm}$, Phys. Med. Biol., 48, 41654172, doi:10.1088/0031-9155/48/24/013, 2003.

McNaughton, C. S., Clarke, A. D., Howell, S. G., Pinkerton, M., Anderson, B., Thornhill, L., Hudgins, C., Winstead, E., Dibb, 
J. E., Scheuer, E., and Maring, H.: Results from the DC-8 Inlet Characterization Experiment (DICE): Airborne Versus Surface Sampling of Mineral Dust and Sea Salt Aerosols, Aerosol Sci. Technol., 41, 136-159, doi:10.1080/02786820601118406, 2007.

Mishchenko, M. I., Travis, L. D., and Lacis, A. A.: Scattering, absorption, and emission of light by small particles, Cambridge university press, 2002.

Muñoz, O., Moreno, F., Guirado, D., Ramos, J. L., Volten, H., and Hovenier, J. W.: The IAA cosmic dust laboratory: Experimental scattering matrices of clay particles, Icarus, 211, 894-900, doi:10.1016/j.icarus.2010.10.027, 2011.

Nessler, R., Weingartner, E., and Baltensperger, U.: Adaptation of dry nephelometer measurements to ambient conditions at the Jungfraujoch, Environ. Sci. Technol., 39, 2219-2228, doi:10.1021/es035450g, 2005.

Orozco, D., Beyersdorf, A. J., Ziemba, L. D., Berkoff, T., Zhang, Q., Delgado, R., Hennigan, C. J., Thornhill, K., Young, D. E., Parworth, C., Kim, H., and Hoff, R. M.: Hygroscopicity Measurements of Aerosol Particles in the San Joaquin Valley, CA, Baltimore, MD, and Golden, CO, J. Geophys. Res.-Atmos., 121, 7344-7359, doi:10.1002/2015JD023971, 2016.

Petters, M. D. and Kreidenweis, S. M.: A single parameter representation of hygroscopic growth and cloud condensation nucleus activity, Atmos. Chem. Phys., 7, 1961-1971, doi:10.5194/acp-71961-2007, 2007.

Pinnick, R. G., Pendleton, J. D., and Videen, G.: Responseor estimating the refractive inde characteristics of the particle measuring systems active scattering aerosol spectrometer probes, Aerosol Sci. Technol., 33, 334-352, doi:10.1080/02786820050121530, 2000.

Redemann, J., Turco, R. P., Liou, K. N., Russell, P. B., Bergstrom, R. W., Schmid, B., Livingston, J. M., Hobbs, P. V., Hartley, W. S., Ismail, S., Ferrare, R. A., and Browell, E. V.: Retrieving the vertical structure of the effective aerosol complex index of refraction from a combination of aerosol in situ and remote sensing measurements during TARFOX, J. Geophys. Res.-Atmos., 105, 9949-9970, doi:10.1029/1999JD901044, 2000.

Schuster, G. L., Lin, B., and Dubovik, O.: Remote sensing of aerosol water uptake, Geophys. Res. Lett., 36, 1-5, doi:10.1029/2008GL036576, 2009.

SEAC4RS: Studies of Emissions and Atmospheric Composition, Clouds and Climate Coupling by Regional Surveys Data Archive, doi:10.5067/Aircraft/SEAC4RS/AerosolTraceGas-Cloud, 2015.

Shingler, T., Crosbie, E., Ortega, A., Shiraiwa, M., Zuend, A., Beyersdorf, A., Ziemba, L., Anderson, B., Thornhill, L., Perring, A. E., Schwarz, Joshua P., Campazano-Jost, P., Day, D. A., Jimenez, J. L., Hair, J. W., Mikoviny, T., Wisthaler, A., and Sorooshian, A.: Airborne characterization of subsaturated aerosol hygroscopicity and dry refractive index from the surface to $6.5 \mathrm{~km}$ during the SEAC4RS campaign, J. Geophys. Res.Atmos., 121, 4188-4210, 2016.

Sultanova, N. G., Nikolov, I. D., and Ivanov, C. D.: Measuring the refractometric characteristics of optical plastics, Opt. Quant. Electron., 35, 21-34, doi:10.1023/A:1021811200953, 2003.
Svenningsson, B., Rissler, J., Swietlicki, E., Mircea, M., Bilde, M., Facchini, M. C., Decesari, S., Fuzzi, S., Zhou, J., Mønster, J., and Rosenørn, T.: Hygroscopic growth and critical supersaturations for mixed aerosol particles of inorganic and organic compounds of atmospheric relevance, Atmos. Chem. Phys., 6, 1937-1952, doi:10.5194/acp-6-1937-2006, 2006.

Sviridenkov, M. A., Vlasenko, S. S., and Nebosko, E. Y.: Retrieval of the aerosol optical and microphysical parameters from the data of measurements by means of Aurora 4000 nephelometer, in: Proc. of SPIE, 20th International Symposium on Atmospheric and Ocean Optics: Atmospheric Physics, edited by: Romanovskii, O. A., 9292, 92922U-1-92922U-6, doi:10.1117/12.2076156, 2014.

Tanaka, M., Takamura, T., and Nakajima, T.: Refractive index and size distribution of aerosols as estimated from light scattering measurements, J. Appl. Meteorol., 22, 1253-1261, 1983.

Tang, I.: Chemical and size effects of hygroscopic aerosols on light scattering coefficients, J. Geophys. Res., 101, 19245-19250, 1996.

Toon, O. B. and Pollack, J. B.: The Optical Constants of several Atmospheric Aerosol Species: Ammonium Sulfate, Aluminium Oxide, and Sodium Chloride, J. Geophys. Res., 81, 5733-5748, 1976.

Toon, O. B., Maring, H., Dibb, J., Ferrare, R., Jacob, D. J., Jensen, E. J., Luo, Z. J., Mace, G. G., Pan, L. L., Pfister, L., Rosenlof, K. H., Redemann, J., Reid, J. S., Singh, H. B., Robert Yokelson, Minnis, P., Chen, G., Jucks, K. W., and Pszenny, A.: Planning, implementation and scientific goals of the Studies of Emissions and Atmospheric Composition, Clouds and Climate Coupling by Regional Surveys (SEAC4RS) field mission, J. Geophys. Res.Atmos., 121, 4967-5009, doi:10.1002/2015JD024297, 2016.

Volten, H., Munoz, O., Rol, E., Haan, J., W, V., and Hovenier, J.: Scattering matrices of mineral aerosol particles at $441.6 \mathrm{~nm}$ and 632.8 nm, J. Geophys. Res., 106, 17375-17401, 2001.

Westphal, D. L. and Toon, O. B.: Simulations of microphysical, radiative, and dynamical processes in a continental-scale forest fire smoke plume, J. Geophys. Res., 96, 22379-22400, doi:10.1029/91jd01956, 1991.

Xu, F., Dubovik, O., Zhai, P.-W., Diner, D. J., Kalashnikova, O. V., Seidel, F. C., Litvinov, P., Bovchaliuk, A., Garay, M. J., van Harten, G., and Davis, A. B.: Joint retrieval of aerosol and waterleaving radiance from multispectral, multiangular and polarimetric measurements over ocean, Atmos. Meas. Tech., 9, 28772907, doi:10.5194/amt-9-2877-2016, 2016.

Yamasoe, M. A., Kaufman, Y. J., Dubovik, O., Remer, L. A., Holben, B. N., and Artaxo, P.: Retrieval of the real part of the refractive index of smoke particles from Sun/sky measurements during SCAR-B, J. Geophys. Res., 103, 31893-31902, doi:10.1029/98JD01211, 1998.

Young, A. T.: Revised depolarization corrections for atmospheric extinction, Appl. Opt., 19, 3427-3428, 1980.

Zhao, F.: Determination of the complex index of refraction and size distribution of aerosols from polar nephelomter measurements, Appl. Opt., 38, 2331-2336, 1999. 